\title{
RIP VS. OSPF ROUTING PROTOCOLS: WHICH ONE IS THE BEST FOR A REAL-TIME COMPUTER NETWORK?
}

\author{
Nuur Wachid Abdul Majid \\ Program Studi Sistem dan Teknologi Informasi \\ Universitas Pendidikan Indonesia \\ Email: nuurwachid@upi.edu \\ Syifaul Fuada \\ Program Studi Sistem Telekomunikasi \\ Universitas Pendidikan Indonesia \\ Email: syifaulfuada@upi.edu
}

\begin{abstract}
The development of modern computer networks for internet access makes routing protocols needed, and it has an essential role in a real-time system. Therefore, the best and most effective routes can be reached. In this short article, we discuss the comparison of two popular routing protocols, i.e., Routing Information Protocol (RIP) and Open Shortest Path First (OSPF) using two network simulators, i.e., Graphical Network Simulator-3 (GNS3) and Enterprise Network Simulation Platform (ENSP). Both of OSPF and RIP routing protocols can be used in the same topology and have differences in the connection time required to connect communication between routers. Thru GNS3 and ENSP, we obtained the comparison result at ideal condition; we found that the OSPF routing protocol (83 ms) has a faster time or efficient in connection than RIP (177 ms). Besides, we found that compared to GNS3 network simulators $(329 \mathrm{~ms})$, the ENSP has a relatively more rapid average time $(94 \mathrm{~ms})$. This work suggests that a Huawei router with ENSP is faster than a Cisco router which is used by GNS3. Hopefully, this information can be refereed by internet network administrators to build real-time computer networks.
\end{abstract}

Keywords: routing protocol; RIP; OSPF; ENSP; GNS3; real-time computer network.

\section{INTRODUCTION}

The building an internet network require several hardware, software, and protocols. In the contemporary internet era nowadays, routing protocol plays a significant role because it determines how router communicate with other routers in sending packets from the optimal path taken; start from the first node to destination node. Therefore, the best and most effective route can be discovered. TCP/IP is a standard protocol that is applied widely to the internet for data exchange mechanisms. Several prior studies done in routing protocol area, such as conducted by M.N. Akhtar, et al. [1] and F. Sarkohaki, et al. [2].

Related to the protocol as aforementioned, routing is generally divided into two categories, namely "static routing" and "dynamic routing." The dynamic routing requires routing protocols in which each routing protocol has an architecture, adaptability, and ability to achieve different convergence circumstances [3]. There are various types of routing protocols, an internet network administrator needs a reference/literature/data about all of the performance comparison; this can be achieved through simulation to find out the necessary information. The simulation can be run over a network simulator with the desired scenarios. They must consider several critical points to build network as needed, such as this following question: "Which strategy is best one (effective \& efficient) to develop real-time computer networks including routing protocols exploitation?".

Dynamic routing protocols are divided into two categories: interior routing protocol (intra-domain) and exterior routing protocol (inter-domain). Interior routing protocol is ordinarily used on autonomous network, that is a network with one control only. It consists of several subnetworks and gateways that are interconnected with each other. Interior routing protocol is implemented over distance vector (e.g., RIP) and link state (e.g., OSPF). Comparisons of both are very striking characteristics, where OSPF depends on bandwidth (cost) that helps to determine the best path on each node while RIP depends on hop counts in determining the best route. There are numerous works on the performance comparison of routing protocols, such as OSPF, EGRP, and RIP using network simulator approach, e.g. GNS 3. According to the literature surveys, we found that GNS 3 is one of the popular simulation software used as a tool for performance measurement. In related topic, T.S. Chou et al. [4] compared the GNS 3 to the packet tracer (PT) software in terms of functionality, capability, and design factors. The GNS 3 and PT are interactive devices that serve the best GUI. Hence, it can be utilized in learning the virtual network design. Both of them have different aspects of usage, but complement each other. PT can be used to combine internal and external 
functions on a network and provide facilities for easy assessment and execute automatically. GNS3 focuses on the host specifications that will be run and tested to understand how the network logic will run as well as expected. A. Balyk et al, [5] used GNS3 simulator to simulate an HTTP server's performance under the latest version of DDOS attacks that are not possible in many cases. Even though GNS3 has the same drawbacks as other simulators, GNS3 supplies a realistic approach to simulate the networks. Hence, it allows to set up all of the various parameters available in the real computer network. One disadvantage that there are very few devices to simulate. So, the realization of more advanced simulations, comparing network results will open a "trending topic" to be explored soon in the future.

M. Jayakumar et al. [6] compared the OSPF to RIP, they claimed that RIP has higher latency results and it has a higher convergence time than OSPF. Thus, RIP is more suitable for small networks. OSPF has faster convergence and more efficient in using bandwidth; therefore, it can reduce its packet loss. OSPF has a higher throughput compared to RIP. Then in terms of reliability and efficiency factors, OSPF is hugely better than RIP. For large networks, OSPF can be chosen. An internet network administrator can select RIP if the network is small size and relatively simple. When OSPF and RIP are implemented jointly on a system, OSPF is highly recommended. Using OPNET simulation, in [7] also sum up that the OSPF network is faster than RIP.

M.S Habib, et al [8] compared the performance of OSPF to EIGRP based on their network convergence (sec) and traffic dropped (packets/sec). The result denotes that EIGRP is faster than OSPF. In line with [8], Y.N. Krishnan and Shobha [9] also verified the EIGRP and OSPF. However, evaluation of routing protocols focuses more on performance which is described as quantitative matrices such as convergence time, Jitter, End-to-End delay, throughput and packet loss via the simulated model. The evaluation results also verified that EIGRP provide better performance than OSPF for real-time applications.

Later, S.U. Masruroh, et al [10] employed GNS 3 to investigate the three protocols performance as mentioned above (i.e., RIP, OSPF, and EIGRP) in an IPv6 network based on following parameters: throughput, jitter, and packet loss. This research outcome indicated that RIP has higher throughput, while the OSPF-EIGRP combination has smaller jitter, and RIP resulted lower packet loss. In more extensive variables, L.D. Circiumarescu et al., [11] analyzed the performance comparison of four routing protocols: RIP, OSPF, EIGRP, and IGRP for real time applications. They employed OPNET software. Evaluation is completely based on different variation aspects: 1) packet delay; 2) packet end-to-end delay; 3) video traffic; 4) download response time; 5) upload response time in Email; 6) FTP; 7) page response time and object response time in HTTP; 8) convergence, and 9) queuing delay. They suggested that EIGRP is the best choice for applications as follow: video conferencing, FTP, e-mail, HTTP, and convergence. Whereas EIGRP is recommended for information dissemination applications from small to medium networks. EIGRP performance is better than IGRP, OSPF, and RIP.

In this paper, we more highlight the performance comparison of RIP and OSPF. We still want to prove by own experimental simulation in order to compare between RIP and OSPF with simple configuration instead of the related to studies that have been conducted by Ref. [4-11]. Several types of routers that are very influential, such as Cisco, TP Link, D-link, and Linksys may be a series of familiar brands and often the best choice router devices. The GNS 3 uses a Cisco router simulation. On the other hand, Huawei also released several multifunctional and performance routers that were not inferior to different types of routers. The ENSP is a simulator network using Huawei router simulation. Hence, we used GNS3 dan ENSP. The routing protocol performance can be identified through the simulation results of the two primary parameters, i.e., the packet delivery time using Ping and the path that was passed using traceroute.

This paper motivation is to compare two popular routing protocols, OSPF and RIP using GNS3 and ENSP network simulators through Ping and Traceroute tests. The results of this paper can be used for a network engineer to select which is the best one for real-time computer network.

\section{METHOD}

\subsection{Limitation Study}

This experiment only focuses on the comparison of OSPF and RIP routing protocols using network simulators. Accordingly, the results are obtained from simulation world. In other words, we get the comparison data in an ideal circumstance. While the real test (laboratory test) will be performed and discussed in further study. 


\subsection{Experimental Set Up}

This work was done by three steps: design, simulation and performance test. We first design the router configuration in the GNS3 and ENSP network simulators as depicted in Fig 1. In this work, we used GN3 (GNS3-0.8.5 -all-in-one) with 3600 (c3640-jk9s-mz.124-16) Cisco router and ENSP V100R002C00B350 with Huawei router. Tests carried out on 7 (seven) routers which the topology is made to resemble a simple local network in which it represents the superiority of the used routing protocol (OSPF and RIP) on IPV4 networks. Four routers (R1, R2, R4, R5) are connected series, and three routers from R3, R6, R7 are also connected series. Later, we connected in parallel configuration, R2 is wired to R3 and R5 is wired to R6.

The long path is as follows: $\mathrm{R} 1-\mathrm{R} 2-\mathrm{R} 4-\mathrm{R} 5-\mathrm{R} 6-\mathrm{R} 7$ (pass of 6 routers), whereas the short path scenario is as follows: R1 - R2 - R3 - R6 - R7 (only pass of 5 routers). As shown in Fig. 1, the configuration is very simple to avoid lower latency and get higher throughput so that the performance test can be obtained real-condition as possible.

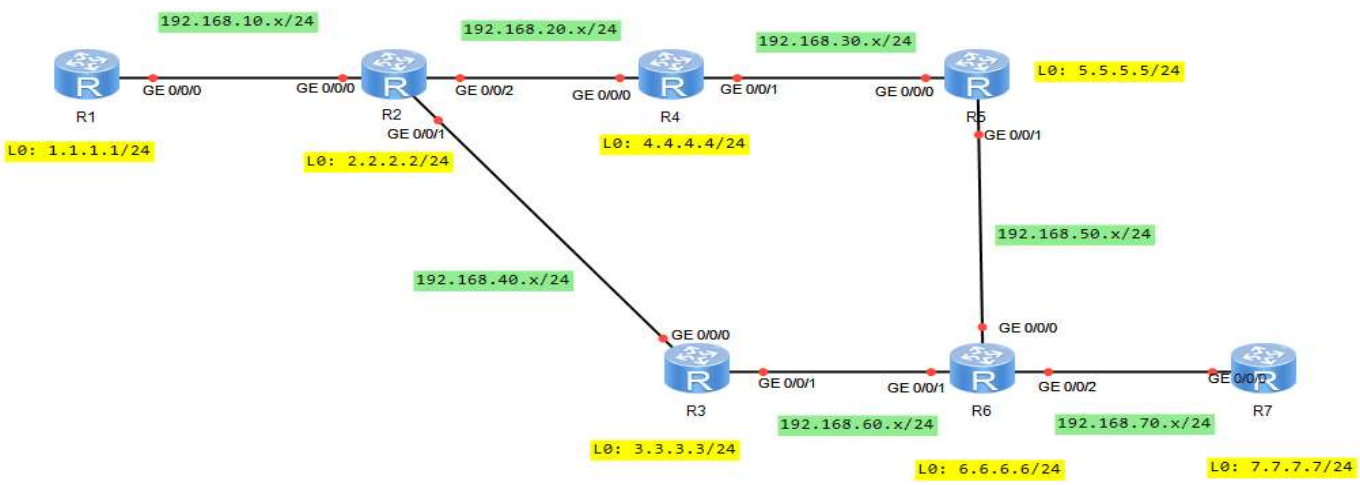

Figure 1. Configuration Scheme Of The Network

We can see that Router 1 is the first point, while Router 7 is the last point of the designed network configuration. The notation "L0" represents router-id, GEx/x/x represents the port name. IP Address is pointed out by 192.xxx.xx.x/xx. This network configuration aimed to provide information about the contents of both routing protocols. Table 1 lists the OSPF and RIP configurations; in this table, we give the information about hostname, router version, router-id, interface, and area. Afterward, we configured the IP address and loopback as describe in Table 2. This configuration is then simulated, we will know that whether it can work properly or not (the ping packet is sent successfully and the network can find the shortest path).

Once the configuration process on each router is complete, next, we perform the package delivery test. There are two test scenarios in this work, namely packet delivery test via the "Ping" and traceroute commands. The "ping" test is done to determine the time needed in data communication on connected routers while the traceroute test aims to find out the shortest path and time required in a communication path from the end of the router to the farthest router.

Table 1. Network configuration of OSPF and RIP

\begin{tabular}{|c|c|c|}
\hline $\begin{array}{l}\text { Routing } \\
\text { Protocol } \\
\end{array}$ & OSPF & RIP \\
\hline Hostname & Name for each router: & Name for each router: \\
\hline $\begin{array}{l}\text { Router } \\
\text { Version }\end{array}$ & $\begin{array}{l}\mathrm{R} 1, \mathrm{R} 2, \mathrm{R} 3, \mathrm{R} 4, \mathrm{R} 5, \mathrm{R} 6 \text {, dan R7 } \\
\text { Router version which is used: } \\
\text { router OSPF } 1\end{array}$ & $\begin{array}{l}\mathrm{R} 1, \mathrm{R} 2, \mathrm{R} 3, \mathrm{R} 4, \mathrm{R} 5, \mathrm{R} 6 \text {, dan R7 } \\
\text { Router version which is used: Router RIP } \\
\text { version } 2\end{array}$ \\
\hline Router-id & $\begin{array}{l}\text { To simplify the router } \\
\text { identification, we set the ID with } \\
\text { four digits, i.e. R1 = router-id } \\
\text { 1.1.1.1. While R2 is router-id } \\
\text { 2.2.2.2. Later, router-id 3.3.3.3 for } \\
\text { R3, until R7 = 7.7.7.7 }\end{array}$ & 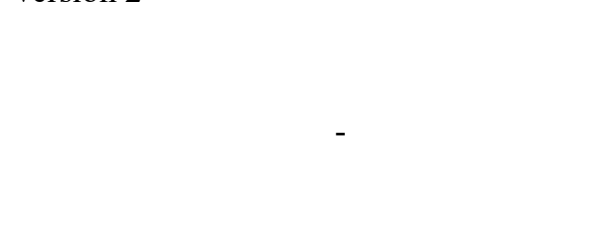 \\
\hline Interface & $\begin{array}{l}\text { Interface FastEthernet and } \\
\text { Interface Loopback0 }\end{array}$ & Interface FastEthernet \\
\hline Area & Area used: OSPF 1 area 0 & - \\
\hline
\end{tabular}


Table 2. IP address and loopback

\begin{tabular}{cccc}
\hline No & Router Name & IP Address & Int LoopBack \\
\hline 1 & Router 1 (R1) & 192.168 .10 .1 & $1.1 .1 .1 / 24$ \\
& & 192.168 .10 .2 & $2.2 .2 .1 / 24$ \\
2 & Router 2 (R2) & 192.168 .20 .1 & $8.8 .8 .1 / 24$ \\
& & 192.168 .40 .1 & \\
3 & Router 3 (R3) & 192.168 .40 .2 & $3.3 .3 .1 / 24$ \\
& & 192.168 .60 .1 & $4.4 .4 .1 . / 24$ \\
4 & Router 4 (R4) & 192.168 .20 .2 & $5.5 .5 .1 / 24$ \\
5 & & 192.168 .40 .1 & \\
& & 192.168 .30 .2 & $6.6 .6 .1 / 24$ \\
6 & & 192.168 .50 .1 & \\
& & 192.168 .50 .2 & $7.7 .7 .1 / 24$ \\
\hline
\end{tabular}

\section{RESULTS AND DISCUSSION}

The development of RIP and OSPF becoming a public concern worldwide because they have different application cases and exciting to be explored more. A routing protocol describes the rules that must be followed by routers that interact with neighboring routers. The RIP and OSPF are the interior gateway routing protocols that have different characteristics. The RIP is a "distance vector" routing protocol category, while the OSPF is an example of "link state" routing. The distance vector routing protocols find the best paths on remote networks through alternative networks. Whereas the link state is also known as the first shortest path. Each router makes three parts of a table, where each table has different functions such as tracking neighbors that are directly connected; specifying the topology on the entire internetwork; and being used for routing tables.

Table 3 shows the ping test result in RIP and OSPF configuration using GNS3 and ENSP network simulators. The Ping test is set to execute 4 (four) times data retrieval for each router communication. This is intended to ensure optimal comparison results (one hundred percent successful). It shows that RIP configuration is slower than OSPF based on the average time attained. It can be proven according to the test result on the nearest router and the farthest router. For example, in the configuration between routers $1-2$, RIP produces an average time of $177 \mathrm{~ms}$ in the final test and $83 \mathrm{~ms}$ for OSPF.

Furthermore, Table 3 exhibits the difference in average time speed for both simulator networks. It can be summarized that the ENSP is faster than GNS3. For example, between routers 1-7 in OSPF configuration: the average time obtained of ENSP and GNS3 are $94 \mathrm{~ms}$ and $329 \mathrm{~ms}$, respectively.

Thus, OSPF is more recommended for real-time computer network applications because it has the convergence speed and the broader reach of networks. This experiment finding corresponds with the research conducted by F. Sabirin and R. Permana [12] that OSPF provides better data transfer time when compared to RIP. Whereas RIP can be implemented on small size networks that the implementation and configuration tend to be simple and easy.

Table 3. Shows the ping test result in RIP and OSPF

\begin{tabular}{|c|c|c|c|c|c|c|c|}
\hline \multirow[b]{2}{*}{ No } & \multirow[b]{2}{*}{$\begin{array}{c}\text { Router } \\
\text { Communication }\end{array}$} & \multirow[b]{2}{*}{$\begin{array}{c}\text { Number } \\
\text { of Test }\end{array}$} & \multicolumn{2}{|c|}{ RIP } & \multicolumn{2}{|c|}{ OSPF } & \multirow[b]{2}{*}{ Success } \\
\hline & & & $\begin{array}{c}\text { Average } \\
\text { Time (ms) } \\
\text { in the } \\
\text { ENSP }\end{array}$ & $\begin{array}{c}\text { Average } \\
\text { Time (ms) in } \\
\text { the GNS } 3\end{array}$ & $\begin{array}{c}\text { Average } \\
\text { Time (ms) } \\
\text { in the } \\
\text { ENSP }\end{array}$ & $\begin{array}{c}\text { Average } \\
\text { Time (ms) in } \\
\text { the GNS } 3\end{array}$ & \\
\hline \multirow{4}{*}{1} & & I & 32 & 94 & 28 & 77 & \multirow{4}{*}{$100 \%$} \\
\hline & Router & II & 38 & 113 & 26 & 97 & \\
\hline & $1-2$ & III & 36 & 214 & 36 & 107 & \\
\hline & & IV & 28 & 177 & 30 & 83 & \\
\hline \multirow{4}{*}{2} & & I & 30 & 129 & 38 & 102 & \multirow{4}{*}{$100 \%$} \\
\hline & Router & II & 42 & 112 & 34 & 144 & \\
\hline & $2-3$ & III & 46 & 164 & 26 & 100 & \\
\hline & & IV & 38 & 175 & 24 & 88 & \\
\hline \multirow{3}{*}{3} & & I & 42 & 130 & 38 & 164 & \multirow{3}{*}{$100 \%$} \\
\hline & Router & II & 36 & 183 & 30 & 142 & \\
\hline & & III & 42 & 156 & 42 & 107 & \\
\hline
\end{tabular}




\begin{tabular}{|c|c|c|c|c|c|c|c|}
\hline \multirow[b]{2}{*}{ No } & \multirow[b]{2}{*}{$\begin{array}{c}\text { Router } \\
\text { Communication }\end{array}$} & \multirow[b]{2}{*}{$\begin{array}{c}\text { Number } \\
\text { of Test }\end{array}$} & \multicolumn{2}{|c|}{ RIP } & \multicolumn{2}{|c|}{ OSPF } & \multirow[b]{2}{*}{ Success } \\
\hline & & & $\begin{array}{c}\text { Average } \\
\text { Time (ms) } \\
\text { in the } \\
\text { ENSP }\end{array}$ & $\begin{array}{c}\text { Average } \\
\text { Time (ms) in } \\
\text { the GNS } 3\end{array}$ & $\begin{array}{c}\text { Average } \\
\text { Time (ms) } \\
\text { in the } \\
\text { ENSP }\end{array}$ & $\begin{array}{c}\text { Average } \\
\text { Time (ms) in } \\
\text { the GNS } 3\end{array}$ & \\
\hline \multirow{6}{*}{4} & & IV & 36 & 174 & 32 & 108 & \multirow{6}{*}{$100 \%$} \\
\hline & & I & 28 & 126 & 40 & 120 & \\
\hline & Router & II & 38 & 132 & 32 & 110 & \\
\hline & $4-5$ & III & 36 & 112 & 30 & 92 & \\
\hline & & IV & 32 & 196 & 38 & 88 & \\
\hline & & I & 42 & 156 & 36 & 97 & \\
\hline \multirow{3}{*}{5} & Router & II & 28 & 112 & 30 & 116 & \multirow{3}{*}{$100 \%$} \\
\hline & $5-6$ & III & 46 & 147 & 40 & 104 & \\
\hline & & IV & 38 & 131 & 36 & 121 & \\
\hline \multirow{4}{*}{6} & & I & 28 & 148 & 34 & 110 & \multirow{4}{*}{$100 \%$} \\
\hline & Router & II & 32 & 203 & 32 & 94 & \\
\hline & $6-7$ & III & 34 & 133 & 32 & 84 & \\
\hline & & IV & 28 & 136 & 32 & 127 & \\
\hline \multirow{4}{*}{7} & & I & 38 & 101 & 36 & 71 & \multirow{4}{*}{$100 \%$} \\
\hline & Router & II & 22 & 121 & 38 & 90 & \\
\hline & $3-6$ & III & 28 & 160 & 20 & 79 & \\
\hline & & IV & 30 & 176 & 28 & 84 & \\
\hline \multirow{4}{*}{8} & & I & 108 & 482 & 106 & 399 & \multirow{4}{*}{$100 \%$} \\
\hline & Router & II & 104 & 366 & 110 & 327 & \\
\hline & $1-7$ & III & 106 & 475 & 86 & 307 & \\
\hline & & IV & 102 & 393 & 94 & 329 & \\
\hline
\end{tabular}

Afterward, we send the data packet with "Traceroute" command, which shows the shortest-path finding process on the created network topology. Table 3 and Table 4 list the obtained average time, it can be concluded that OSPF is faster than RIP. The path taken is not through routers R4 and R5, but immediately takes router R3 then goes to R6. Fig 2 to Fig 5 visualize the traceroute process at the RIP and OSPF configurations with the configuration as shown in Fig. 1.

These screenshoots are a sample of command promt results, which gives readers an understanding of how we obtained data as shown in Tables III, IV, and V. Since there is no method to list the connectiontime automatically, so we note it manually by observing carefully to the results on recording data to keep it valid as possible.

Table 4. Traceroute test using ENSP

\begin{tabular}{ccccc}
\hline No & Router trace & $\begin{array}{c}\text { Number of } \\
\text { Test }\end{array}$ & $\begin{array}{c}\text { Time I } \\
(\mathbf{m s})\end{array}$ & $\begin{array}{c}\text { Time II } \\
(\mathbf{m s})\end{array}$ \\
\hline \multirow{4}{*}{1} & Method of OSPF & I & 110 & 110 \\
Router & II & 110 & 110 \\
& $1-7$ & III & 130 & 110 \\
& & IV & 100 & 90 \\
& (The farthest router distance) & V & 110 & 100 \\
& & VI & 90 & 100 \\
& Methods of RIP & I & 150 & 110 \\
& Router & II & 160 & 100 \\
& $1-7$ & III & 130 & 140 \\
& & IV & 130 & 150 \\
& & V & 110 & 100 \\
& & VI & 110 & 90 \\
\hline
\end{tabular}


Table 5. Traceroute Test Using GNS3

\begin{tabular}{ccccc}
\hline No & Router trace & $\begin{array}{c}\text { Number of } \\
\text { Test }\end{array}$ & $\begin{array}{c}\text { Time I } \\
(\mathbf{m s})\end{array}$ & $\begin{array}{c}\text { Time II } \\
(\mathbf{m s})\end{array}$ \\
\hline \multirow{4}{*}{1} & Method of OSPF & I & 268 & 388 \\
& Router & II & 540 & 524 \\
& $1-7$ & III & 388 & 280 \\
& & IV & 316 & 580 \\
& (The farthest router distance) & V & 400 & 348 \\
& & VI & 384 & 392 \\
& & I & 380 & 848 \\
& Method of RIP & II & 572 & 432 \\
& Router & III & 256 & 540 \\
& $1-7$ & IV & 388 & 464 \\
& & V & 468 & 932 \\
& & VI & 500 & 772 \\
\hline
\end{tabular}

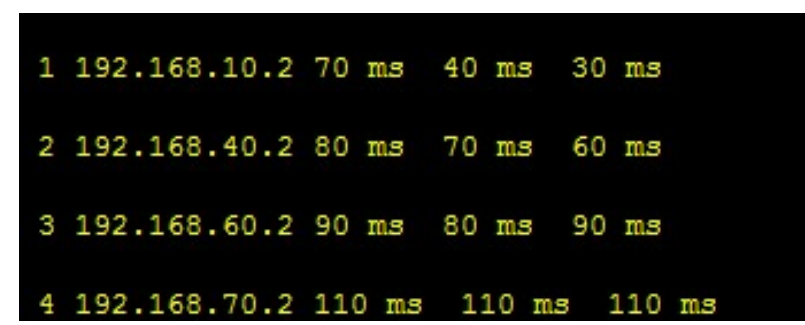

Figure 2. Traceroute Test of OSPF Protocol Using ENSP

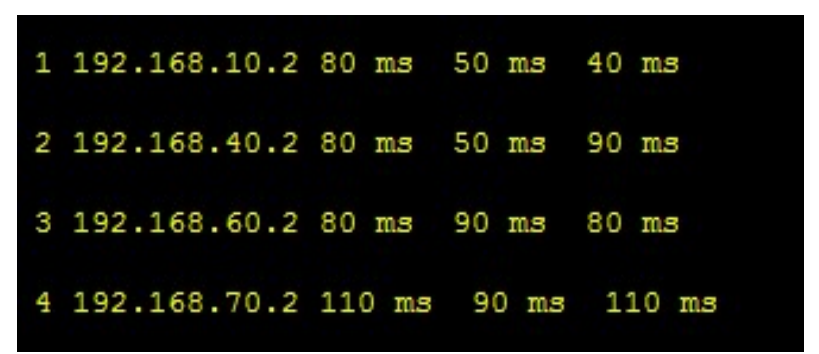

Figure 3. Traceroute Test of RIP Protocol Using ENSP

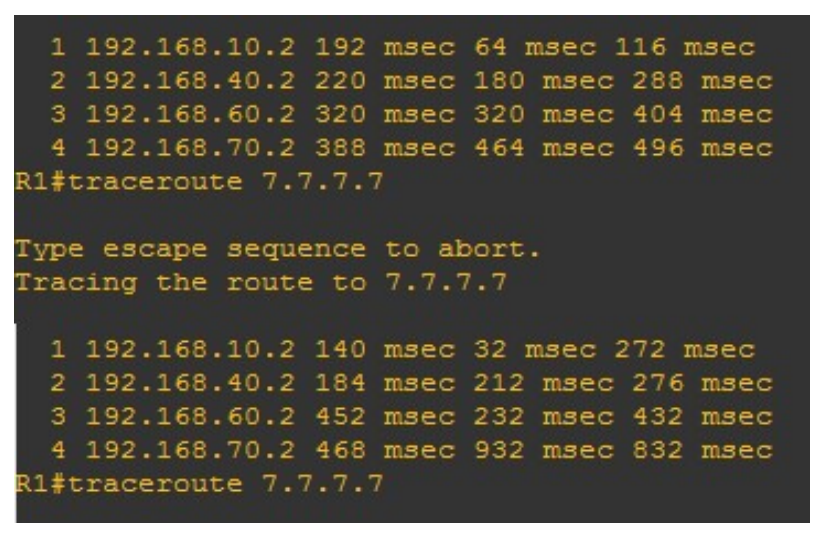

Figure 4. Traceroute of OSPF Protocol Using GNS 3 


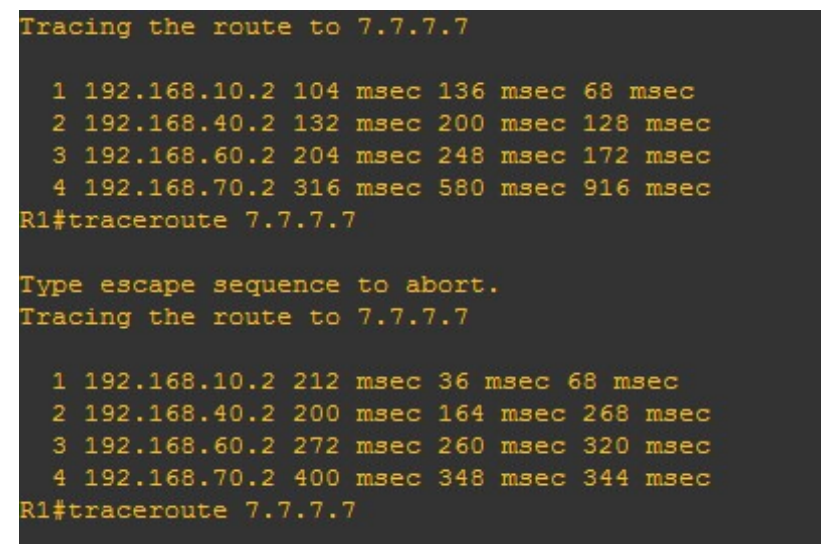

Figure 5. Traceroute of RIP Protocol Using GNS 3

\section{CONCLUSION}

Referring to the simulation test, we confirm that OSPF has a faster time-efficiency than RIP. Moreover, the result states that ENSP has a relatively faster average time than GNS3, it means that ENSP performs better than GNS3. The OSPF routing protocol can be employed for real-time computer network viewing from the data packets that were successfully sent and data transmission times (lower cost transmission). Also, in accordance with Ref. [13], the OSPF serves maximum throughput, most moderate queuing delay and suitable for more extensive networks. This conclusion confirms the valid data because it corelates with existing research results as elaborated in [14] [15]. We hope this paper contents can be used as a supplementary reference for internet network engineers and also network administrators. Further, we will address the same experimental setup containing various matrices, such as bandwidth usage, resources usage, multiple path support, scalability, patented, non-IP protocol, and so on.

\section{REFERENCES}

[1] Akhtar M N Ali A Ali Z Hashmi M A and Atif M, 2018 Cluster based routing protocols for wireless sensor networks: an overview Int. J. Adv. Comput. Sci. Appl. 9, 12 p. 389-396.

[2] Sarkohaki F Fotohi R and Ashrafian V, 2017 An efficient routing protocol in mobile ad-hoc networks by using artificial immune system Int. J. Adv. Comput. Sci. Appl. 8, 4.

[3] Purnomo M F E Andari D Y S and Pramono S H, 2013 Simulasi Kinerja Routing Protokol Open Shortest Path First (Ospf) Dan Enhanced Interior Gateway Routing Protocol (Eigrp) Menggunakan Simulator Jaringan Opnet Modeler V. 14.5 urnal Mhs. Tek. Elektro Univ. Brawijaya 1, 2 p. 1-6.

[4] Chou T-S Baker S K and Vega-Herrera M, 2016 A Comparison of Network Simulation and Emulation Virtualization Tools in 2016 ASEE Annual Conference \& Exposition.

[5] Balyk A Karpinski M Naglik A Shangytbayeva G and Romanets I, 2014 Using Graphic Network Simulator 3 for DDOS Attacks Simulation Int. J. Comput. 16, 4 p. 219-225.

[6] Jayakumar M Rekha N R S and Bharathi B, 2015 A comparative study on RIP and OSPF protocols in 2015 International Conference on Innovations in Information, Embedded and Communication Systems (ICIIECS), Coimbatore p. 1-5.

[7] A S and Rana W J, 2013 Performance Analysis of RIP and OSPF in Network Using OPNET Int. J. Comput. Sci. Issues 10, 6 p. 256-265.

[8] Habib M. Shehu H A and Bello I, 2018 Performance Analysis of EIGRP and OSPF Routing Protocols for a Client Network Int. J. Adv. Acad. Res. 4, 7 p. 46-56.

[9] Krishnan Y N and Shobha G, 2013 Performance Analysis of OSPF and EIGRP Routing PRotocols for Greener Internetworking in International Conference on Green High Performance Computing (ICGHPC) p. $1-4$.

[10] Masruroh S U Robby F and Hakiem N, 2016 Performance evaluation of routing protocols RIPng, OSPFv3, and EIGRP in an IPv6 network in International Conference on Informatics and Computing (ICIC) p. 111-116.

[11] Circiumarescu L D Predusca G Angelescu N and Puchianu D, 2015 Comparative Analysis of Protocol RIP, OSPF, RIGRP and IGRP for Service Video Conferencing, E-mail, FTP, HTTP in 20th International Conference on Control Systems and Computer Science p. 584-589.

[12] Sabirin F and Permana R, 2017 Perbedaan routing menggunakan routing information protocol (RIP) 
dengan Open Shortest Path First (OSPF) Cybernetics 1, 2 p. 120-130.

[13] Techdifferences, 2017, Difference between RIP and OSPF.

[14] Dumitrache C G Predusca G Circiumarescu L D Angelescu N and Puchianu D C, 2017 Comparative study of RIP, OSPF, and EIGRP prototols using Cisco packet tracker in 5th International Symposium on Electrical and Electronics Engineering (ISEEE) p. 1-6.

[15] Ajani A A Ojuolape B J Ahmed A A Aduragba T and Balogun M, 2017 Comparative performance evaluation of open shortest path first, OSPF and routing information protocol, RIP in network link failure and recovery cases in IEEE 3rd International Conference on Electro-Technology for National Development (NIGERCON) p. 280-288. 